$16^{\circ}$ USIHC - Congresso Internacional de Ergonomia e Usabilidade de

\title{
O DESIGN CENTRADO NO USUÁRIO E A USABILIDADE: UMA PROPOSTA DE APLICATIVO PARA CELULAR
}

\section{THE USER CENTERED DESIGN AND USABILITY: APROPOSAL FOR MOBILE APPLICATION}

\author{
Jéssica Araujo ${ }^{1}$ \\ Milena Pereira $^{2}$ \\ Victor Gabriel Sousa ${ }^{3}$ \\ Lívia Flávia Campos ${ }^{4}$, Dra \\ (1) UFMA \\ e-mail:.jessica.ra@live.com \\ (2) UFMA \\ e-mail: milenacp@live.com \\ (3) UFMA \\ e-mail:vgabriel766@gmail.com \\ (4.) UFMA \\ e-mail: liviaflavia@gmail.com
}

Palavras-chave: usabilidade, design, aplicativo.

Resumo: Este artigo relata o desenvolvimento e avaliação, com foco no Design Centrado no Usuário e usabilidade, da interface de um jogo. Foi utilizada uma abordagem participativa. Foi desenvolvido o layout e por fim um protótipo do aplicativo. Os resultados apontam que através da abordagem participativa pode-se permitir uma melhor adaptação às necessidades dos usuários.

\section{Key-words: usability, design, mobile app}

Abstract: This article reports on the development and evaluation, focusing on User Centered Design and usability, of the interface of a game. A participatory approach was used. The layout was developed and finally a prototype application. The results indicate that through the participatory approach one can allow a better adaptation to the needs of the users. 


\section{Introdução}

As inovações tecnológicas evoluem juntamente com o design, o que resulta em uma propagação de conhecimento. Do papiro ao papel, do computador ao smartphone, cada tecnologia acaba que por desenvolver uma linguagem visual própria. Dessa maneira, a evolução da tecnologia e do design é revelada nas interfaces produzidas ao longo dos séculos (PASSOS 2010). Interfaces essas, que passam a refletir o nível de desenvolvimento das sociedades.

Sempre que um designer projeta uma interface, se leva em consideração a faixa etária, localização geográfica, formação educacional e a cultura do usuário. Para que seja fácil de usar, trabalhar de maneira prevista e ser consistente durante todo o processo de interação independente do usuário (BRANDÃO \& MORAES, 2006).

A Interação humano-computador, ou IHC, tem um importante papel no projeto e no desenvolvimento de todos os tipos de sistemas computadorizados, como controle de tráfego aéreo, processamento nuclear, aplicativos de escritório ou jogos (games) (BRANDÃO \& MORAES, 2006).

Sendo assim, o objetivo geral do artigo concentra-se emdesenvolver uma proposta de um jogo interativo de perguntas e respostas para smartphone, considerando os princípios do Design centrado no Usuário e IHC e avaliar os critérios de usabilidade da proposta de interface.

\section{Referencial Teórico}

\subsection{Aplicativos móveis}

O ano de 2007, marcado pelo lançamento do primeiro dispositivo mobile da Apple, o iphone, revolucionou o mercado de telecomunicações mundial ao reinventar e redefinir o conceito de smartphone. Para adiante, então, observarmos o que foi considerado por alguns autores como o início de uma nova era, pautada por alterações profundas no modo como as pessoas se relacionam e, consequentemente, no modo como as empresas se relacionam com as pessoas (COUTINHO, 2014).

Segundo Porto (2012) Aplicativos mobile ou apps são softwares que desempenham objetivos específicos em smartphones e tablets. É possível acessá-los por meio de suas "lojas de aplicativos", como a App Store, Android Market, Play Store, entre outros. Alguns aplicativos são gratuitos, e outros pagos. Normalmente são destinados a dispositivos como iPhone, iPad, Windows Phone ou Android, mas também podem ser baixados para computadores como laptops ou desktops. Os aplicativos são destinados a facilitar o desempenho de atividades do usuário, para diversas finalidades. Porto (2012) classifica os aplicativos mobile em:

- Serviços: fornecem informações e conteúdo de modo simplificado e ágil, como aplicativos para previsões do tempo, navegação de mapas ou até solicitar algum serviço.

- Informações: acesso a conteúdos atualizados em tempo real ou que têm utilidade permanente, como guias de compras/lojas, telefones úteis, promoções, consulta de produtos, entre outros.

- Comunicação: permitem a conexão entre pessoas, como o Skype, Whatsapp ou aplicativos de integração com as redes sociais.

- Entretenimento: destinado para diversão. A indústria de jogos é a que tem maior faturamento entre todos os segmentos do entretenimento. Os aplicativos favorecem ainda mais esse crescimento, pois permitem uma integração perfeita com os jogos.

\subsection{Jogos para aplicativos móveis}

O simples ato de jogar de acordo com Moreira (2011) é capaz de desenvolver na pessoa potencialidades como entreter, aprender, memorizar e interagir. Durante milênios foram surgindo diferentes formas e tipos de jogos variando de acordo com o seu propósito e a cultura referente. $\mathrm{Na}$ atualidade prevalece o jogo do tipo eletrônico. 
Com a popularização dos dispositivos móveis, o mercado de jogos para dispositivos móveis tem experimentado um crescimento bastante significativo nos últimos anos, em 2006 alcançou a marca dos 3 bilhões de dólares (PRADO, 2007 apud PEREIRA, 2012) .

Outro ponto que justifica a popularização é a integração com as redes sociais. Cabral e Couto (2014) apontam que games se aproveitam do potencial da internet móvel e associam sua própria dinâmica a esses serviços. Os aplicativos utilizam desta estratégia para que o jogador de certa forma possa interagir com seus amigos ao compartilhar no facebook, por exemplo, e além do fato de divulgar o jogo e atrair mais usuários. Com base neste sucesso e ascensão é válido o estudo de interface para jogos. $\mathrm{O}$ aplicativo terá além da função de entretenimento, servirá como ferramenta de aprendizado.

\subsection{Usabilidade de aplicativos móveis}

De acordo com a ISO 9241 usabilidade é "a capacidade que um sistema interativo oferece a seu usuário, em determinado contexto de operação, para a realização de tarefas de maneira eficaz, eficiente e agradável". Dessa forma ao desenvolver uma interface se deve ter como objetivo um melhor resultado na interação e a satisfação do usuário.

O psicólogo Donald Norman (2002 apud Passos, 2010), sócio da Nielsen e Bruce Tognazzini na N/N Group, empresa de consultoria em usabilidade, apresenta alguns princípios de design para a construção de interfaces de sistemas interativos.

a) visibilidade - para que o usuário saiba como proceder, as funções devem estar visíveis;

b) feedback - o devido retorno das ações auxilia o usuário a continuar a tarefa, podendo a resposta ser verbal e/ou visual ou de áudio;

c) restrições - inibir as opções de menu em alguns momentos pode evitar que o usuário faça opções incorretas e reduz a chance de erros;

d) mapeamento - as convenções na interface devem atentar às simbologias comuns presentes na vida natural do usuário;

e) consistência - a interface deve ter um padrão, onde operações e elementos semelhantes correspondam a tarefas similares, para que seja mais fácil para o usuário aprender a usá-la;

f) affordance - quando o objeto é auto explicável, quando a forma de interação é evidente.

Outro quesito importante para a usabilidade é a navegação, Nielsen (2000 apud Passos, 2010) aponta que a solução consiste na resposta de três perguntas: Onde estou? Onde estive? Onde posso ir? Se o usuário conseguir responder com facilidade estas perguntas o aplicativo terá uma navegação bem resolvida. Normalmente um aplicativo bem sucedido apresenta um funcionamento fácil de aprender.

\section{Design Centrado no Usuário}

De acordo com Abras, Maloney-Krichmar e Preece (2004, p.1 apud Kulpa, Pinheiro e da Silva, 2011), o termo Design Centrado no Usuário (DCU) se originou em uma pesquisa realizada na Universidade da Califórnia em 1980, onde Donald Norman reconhece que para a construção de um design efetivo é necessário que se leve em consideração os interesses e necessidades do usuário.

Rubin (1994) afirma que o DCU é uma forma em que se coloca o usuário no centro do processo para o desenvolvimento de produtos interativos onde são consideradas as características, necessidades e desejos das pessoas que efetivamente usarão tais produtos. Todas as experiências que o usuário tem enquanto utiliza uma interface deveriam ser o resultado de uma decisão do designer, para Garret (2010 apud Kulpa, Pinheiro e da Silva, 2011) o design centrado no usuário é um processoqueasseguraqueestas experiências não sejam frutos do acaso ou deacidentes, sendo necessário criar uma experiência coesa, intuitiva e, principalmente, prazerosa na utilização da interface.

Gould e Lewis (1985, apud Rubin, 1994) citam três princípios para o DCU: 
- Manter o foco no usuário e em suas tarefas desde o início do projeto;

- Medir a facilidade de uso e de aprendizado do produto desde o princípio do projeto, realizando testes em protótipos com usuários reais e analisando os resultados obtidos;

- Testar a todo o momento os modelos conceituais que estão sendo criado, fazer as modificações necessárias e testar novamente para se chegar a um resultado satisfatório.

Portanto o DCU se divide em etapas de análise, especificação, prototipação e avaliação. Loureiro (2008) define cada etapa da seguinte forma: a análise realizada no começo do processo, no qual se identifica os usuários finais. A especificação descreve como será a interação do usuário com o produto, para que se atinjam seus objetivos. A prototipação, fase que são construídas interfaces que representam as especificações feitas. Etapa de avaliação é realizada os testes com os usuários para validade as loções propostas nos protótipos.

\section{Métodos e Técnicas}

Para o planejamento da interface do aplicativo, foiutilizada uma abordagem participativa e para isto foram usadas às técnicas do cardsorting, wireframe, protótipo de papel e questionário.Após o desenvolvimento do layout, foram aplicados testes de usabilidade, técnica que busca compreender como se dá, de fato, a interação entre o usuário e o produto, a fim de que sejam colhidos feedbacks importantes para melhorias e compreensão o projeto.

\subsection{O cardsorting}

O principal objetivo do cardsorting é compreender a representação mental do conhecimento dos usuários e como estes usuários modelam determinado domínio. Cybis et al. (2007), enxergam esse objetivo já aplicado ao design de sistemas, afirmando que o cardsorting é empregado para descobrir a representação ou modelo mental que os usuários elaboram sobre o conjunto de itens de informação pretendidos para um programa ou aplicação. Santa Rosa \& Moraes (2012) acrescentam a estes objetivos aspectos mais operacionais e observáveis, listando os seguintes propósitos de aplicação do cardsorting:

- Identificar a terminologia que usuários compreendem mais facilmente;

- Identificar os itens difíceis de classificar;

- Identificar informações que possam pertencer a mais de um grupo;

- Perceber como diferentes públicos-alvo categorizam o conteúdo;

- Perceber como cada perfil de usuário pode acessar determinado conteúdo.

\subsection{Protótipo em papel}

Snyder (2003) conceitua "protótipo de papel" como uma forma de variação dos testes de usabilidade onde os usuários têm a possibilidade de desenvolverem tarefas reais através de um processo interativo com uma versão em papel das interfaces propostas, sendomanipulada através de uma pessoa "simulando um computador" que não explicita o modo comoa interface foi planejada para trabalhar, fazendo com que o usuário possa fazer suas escolhas sem interferência.

As vantagens para o uso de protótipos de papael são:

- Fornece feedback ao usuário no início do desenvolvimento do processo, antes que possa investir esforço e recursos para implementação.

- Promove o desenvolvimento iterativo rápido.

- Não requer nenhuma habilidade técnica.

\subsection{Wireframe}

Wireframe é um esqueleto do projeto, que prevê as posições, campos e funcionalidades de um site. É um guia de interface que sugere a estrutura e as relações entre suas páginas. Ele serve como um modelo para estrutura, conteúdo e funcionalidade.

Wodtke e Govella (2009) conceituam wireframe como o modelo esquemático básico de uma tela específica, elaborado para indicar seus elementos, as 
$16^{\circ}$ Ergodesign -Congresso Internacional de Ergonomia e Usabilidade de Interfaces Humano Tecnológica: Produto, Informações Ambientes Construídos e Transporte

$16^{\circ}$ USIHC - Congresso Internacional de Ergonomia e Usabilidade de Interfaces Humano Computador

CINAHPA | 2017 -Congresso Internacional de Ambientes Hipermídia para Aprendizagem.

interações e hierarquia. $\mathrm{O}$ wireframe pode ser criado com diferentes técnicas. As técnicas vão desde desenho a lápis no papel, papéis colados, desenho em ferramentas vetoriais a desenho em ferramentas especializadas para a criação de wireframes.

$\mathrm{O}$ wireframe deste projeto foi desenvolvido a partir dos resultados obtidos na aplicação dos testes pelo método de cardsorting utilizando o aplicativo AxureRp.

\subsection{Questionário}

Nielsen (1993) afirma que a usabilidade tem como objetivo planejar interfaces capazes de permitir que o usuário possa ter uma interação fácil, agradável, com eficácia e eficiência. Ela deve capacitar a criação de interfaces fáceis de maneira a não dificultar o processo, permitindo ao usuário pleno controle do ambiente sem se tornar um obstáculo durante a interação.

A usabilidade pode ser dividida em cinco critérios básicos (Nielsen, 1993):

Intuitividade - $\mathrm{O}$ sistema deve permitir a facilidade de uso de forma que, mesmo sem experiência, o usuário seja capaz produzir algum trabalho satisfatoriamente.

Eficiência - O sistema deve ser eficiente em seu desempenho apresentando um alto nível de produtividade.

Memorização - Suas telas devem apresentar facilidade de memorização permitindo que usuários ocasionais consigam utilizá-lo mesmo depois de um longo intervalo de tempo.

Erro - A quantidade de erros apresentados pelo sistema deve ser o mais reduzido possível, além de apresentarem soluções simples e rápidas mesmo para usuários iniciantes. Erros graves ou sem solução não podem ocorrer.

Satisfação - O sistema deve agradar ao usuário, sejam eles iniciantes ou avançados, permitindo uma interação agradável.
Com isso foi realizado um teste para avaliar o aplicativo desenvolvido, serão apresentadas as medidas coletadas durante o teste e as respostas aos questionários propostos aos usuários. Em seguida, será feita a análise dos possíveis problemas de usabilidade da interface utilizando os dados previamente expostos.

Abaixo está o modelo e as respostas dos usuários ao questionário de avaliação do sistema, em que o usuário deveria responder após o teste com os protótipos de papel, onde as respostas eram numa escala de 0 a 5 , sendo 0 como parâmetro negativo e 5 do mais positivo, além do questionário com três perguntas que consistia nas opiniões e sugestões dos usuários. Este questionário foi feito com base no teste de Ferreira (2002).

\begin{tabular}{|c|c|c|c|c|}
\hline a) & \multicolumn{4}{|c|}{ Facilidade de utilização } \\
\hline Difícil & & & & Fácil \\
\hline 0 & 2 & 3 & 4 & 5 \\
\hline b) & \multicolumn{4}{|c|}{ Organização das informações } \\
\hline Ruim & & & & Boa \\
\hline 0 & 2 & 3 & 4 & 5 \\
\hline c) & \multicolumn{4}{|l|}{ Layout das telas } \\
\hline Confuso & & & & Claro \\
\hline 0 & 2 & 3 & 4 & 5 \\
\hline d) & \multicolumn{4}{|c|}{$\begin{array}{l}\text { Nomenclatura utilizada nas telas (nome de } \\
\text { comandos, títulos, campos, etc.) }\end{array}$} \\
\hline Confuso & & & & Claro \\
\hline 0 & 2 & 3 & 4 & 5 \\
\hline e) & Assimilação das & ma & & \\
\hline Difícil & & & & Fácil \\
\hline 0 & 2 & 3 & 4 & 5 \\
\hline
\end{tabular}


$16^{\circ}$ Ergodesign -Congresso Internacional de Ergonomia e Usabilidade de Interfaces Humano Tecnológica: Produto, Informações Ambientes Construídos e Transporte

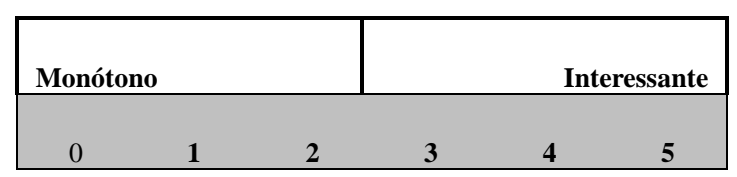

Tabela 01: Modelo do questionário Fonte: Dados de Pesquisa

Perguntas do questionário discursivas retiradas de Ferreira (2002):

Questão 1 - Aponte situações que você achou fácil utilizar o aplicativo?

Questão 2 - Aponte situações em que sentiu dificuldades.

Questão 3 - Sugestão de melhorias.

A realização do teste apontará se o aplicativo atende ao público, se ele cumpre sua tarefa de entreter e informar de forma intuitiva e prática.

\subsection{Teste de usabilidade}

A avaliação do aplicativo foi feita através do método denominado Teste de Usabilidade (Baranauskas \& Rocha, 2000). Este método foi escolhido para esta avaliação por envolver usuários reais nos procedimentos de interação permitindo avaliar e identificar erros podendo atingir resultados mais relevantes.

\subsubsection{Perfil do usuário}

Por se tratar de um jogo em formato quizz para smartphone que aborda o tema política, o teste buscou ser realizado com pessoas que fossem usuárias de smartphone e tivesse familiaridade com este tipo de plataforma de jogo. Afinal este será o público-alvo do aplicativo.

O teste foi realizado com a amostra de cinco pessoas, todos universitários, entre 21 e 24 anos de idade, sendo duas do sexo feminino e três do gênero masculino.

\subsubsection{Lista de Tarefas}

Para a realização do teste foi narrado um cenário para contextualizar o usuário ao teste e com isso realizar as seguintes tarefas:

$$
\begin{aligned}
& \text { - } \quad \text { Logar e iniciar um novo jogo; } \\
& \text { - } \quad \text { Desativar a vibração do jogo; } \\
& \text { - } \quad \text { Compartilhar os pontos em uma rede social; } \\
& \text { Fazer o logout do jogo. }
\end{aligned}
$$

As tarefas eram narradas e o usuário deveria realizalas de forma intuitiva, sem auxílios ou interferência do Avaliador. Como se estivesse sozinho com seu smartphone e utilizando a plataforma no mesmo.

\subsubsection{O Ambiente}

O teste foi realizado em uma sala fechada simulando um local de convívio dos universitários.

O protótipo foi feito em papel, no tamanho real de um smartphone, o usuário interagia com o protótipo e narrava em voz alta seus pensamentos, emoções e ações.

\subsubsection{Envolvidos no Teste}

Além do usuário que realizou os testes estavam presentes no cenário: o facilitador, o computador e o observador.

O facilitador era o responsável por interagir com o usuário, narrando as tarefas e situações para envolver a pessoa no teste, fazendo com que esta se sentisse a vontade no ambiente;

O computador representava o sistema do celular, ou seja, colocava as telas do aplicativo à medida que a pessoa ia interagindo com o protótipo. Essa pessoa não poderia demonstrar emoções e nem interagia com o usuário em forma verbal.

O observador era responsável em registrar as ações do usuário, também não interagia com ninguém no ambiente para não causar distrações.

\section{Resultados}

\subsection{Cardsorting}

Realização:
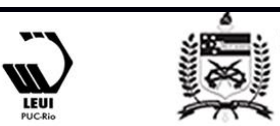
$16^{\circ}$ Ergodesign -Congresso Internacional de Ergonomia e Usabilidade de Interfaces Humano Tecnológica: Produto, Informações Ambientes Construídos e Transporte

$16^{\circ}$ USIHC - Congresso Internacional de Ergonomia e Usabilidade de Interfaces Humano Computador

CINAHPA | 2017 -Congresso Internacional de Ambientes Hipermídia para Aprendizagem.

Para o desenvolvimento dos cardsorting foram escolhidas 30 palavras que seriam ações e comandos existentes no aplicativo. As 30 palavras foram aplicadas online no Optimal Workshop onde um grupo de 10 participantes organizaram os cards de acordo com sua similaridade.

Como resultado tem-se o protótipo da arquitetura da informação de um sistema que pode ser aplicado no aplicativo.

\begin{tabular}{|c|c|c|c|c|}
\hline Sons & Vibração & Música & Idioma & $\begin{array}{l}\text { Tamanho } \\
\text { de Texto }\end{array}$ \\
\hline Notificações & Senha & $\begin{array}{c}\text { Termos de } \\
\text { Serviços }\end{array}$ & Políticas & Feedback \\
\hline Avaliar & Suporte & $\begin{array}{c}\text { Sobre o } \\
\text { Jogo }\end{array}$ & $\begin{array}{l}\text { Mais } \\
\text { Jogos }\end{array}$ & Jogar \\
\hline $\begin{array}{c}\text { Continuar } \\
\text { Jogo }\end{array}$ & Jogo Novo & Mensagem & Conquistas & Bônus \\
\hline Pontos & Ranking & Publicar & Conectar & Próxima \\
\hline $\begin{array}{l}\text { Revelar } \\
\text { Resposta }\end{array}$ & $\begin{array}{c}\text { Nome de } \\
\text { Usuário }\end{array}$ & $\begin{array}{c}\text { Sair: } \\
\text { Sim/Não }\end{array}$ & Instruções & Loja \\
\hline
\end{tabular}

Tabela 02:Cartões escolhidos para a pesquisa Fonte: Dados de Pesquisa

Participaram da pesquisa 10 pessoas, sendo dois homens jovens experientes, duas mulheres jovens experientes, dois homens adultos inexperientes, duas mulheres adultas inexperientes e dois especialistas.

Percebendo como cada usuário identificou os rótulos, foram percebidas algumas palavras de difíceis compreensões e outras participando em mais de um grupo.Com o resultado da pesquisa obteve-se o protótipo da arquitetura da informação do sistema.

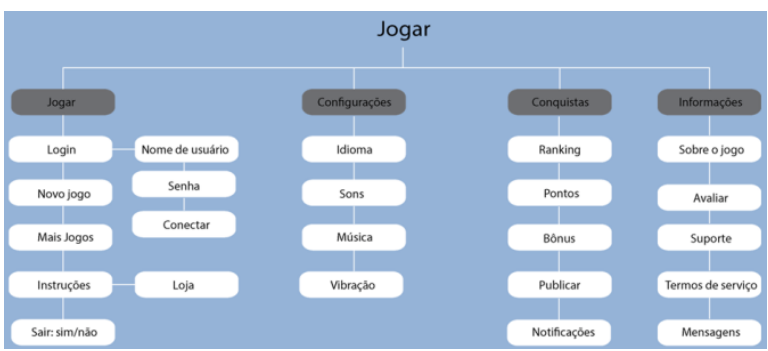

Figura 01 - Protótipo da arquitetura da informação do sistema.

Fonte: Dados de Pesquisa

\subsection{Wireframe}

O wireframe é o esqueleto do projeto, que permite definir a hierarquia de informação. É um diagrama bidimensional em preto e branco que sugere a estrutura que irá compor uma interface. $\mathrm{O}$ wireframe foi feito no site online AxureRP. Com link http://oen5n8.axshare.com/\#p=tela_inicial

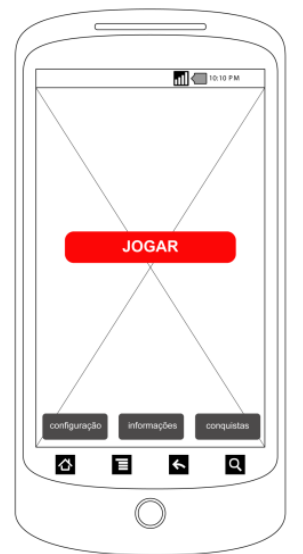

Figura 02 - Exemplo da tela desenvolvida em wireframe

Fonte: Dos autores.

\subsection{Protótipo de Papel}

Para o protótipo foi utilizado à prototipagem de papel que é uma técnica que permite criar e testar interfaces de usuário de forma rápida e barata que geram um excelente feedback de observação sobre o comportamento do usuário.

O layout para as interfaces do aplicativo foi desenvolvido após pesquisas para pictogramas, escolhidas as cores e tipografias que representavam o Reino Unido e sua cultura.

Para a tipografia, foi utilizada a "RAILWAY" por ser a tipografia utilizada na estação de metro de Londres.As cores azul, vermelho e branco fazem referencia às cores utilizadas na bandeira da Inglaterra.Para os pictogramas, foram usados como 
$16^{\circ}$ Ergodesign -Congresso Internacional de Ergonomia e Usabilidade de Interfaces Humano Tecnológica: Produto, Informações Ambientes Construídos e Transporte

$16^{\circ}$ USIHC - Congresso Internacional de Ergonomia e Usabilidade de Interfaces Humano Computador

CINAHPA | 2017 -Congresso Internacional de Ambientes Hipermídia para Aprendizagem.

referências os principais pontos turísticos da Inglaterra.

A partir do desenvolvimento gráfico, obteve-se o seguinte layout:

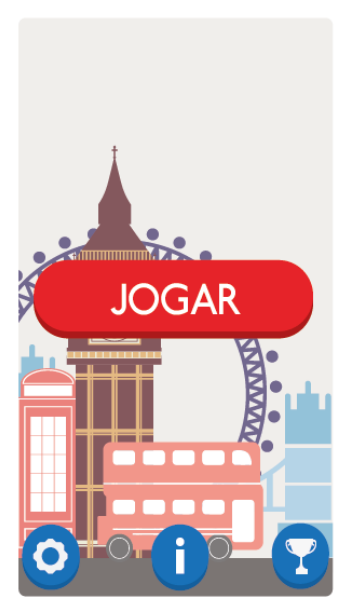

Figura 03 - Exemplo da tela do layout desenvolvido para o aplicativo.

Fonte: Dos autores.

\subsection{Resultados dos testes}

\subsubsection{Tempo de execução das tarefas}

Todos os cinco usuários conseguiram cumprir as quatro tarefas propostas, na tabela 01 pode-se observar o tempo para cada tarefa e suas médias.Com base nisso é possível fazer algumas conclusões.

\begin{tabular}{|c|c|c|c|c|}
\hline \multicolumn{5}{|c|}{ MÉDIA POR TAREFA } \\
\hline TAREFAS & $\mathbf{1}$ & $\mathbf{2}$ & $\mathbf{3}$ & LOGOUT \\
\hline $\begin{array}{c}\text { USUÁRIO } \\
\mathbf{0 1}\end{array}$ & $00: 00: 46$ & $00: 00: 34$ & $00: 01: 00$ & $00: 00: 06$ \\
\hline $\begin{array}{c}\text { USUÁRIO } \\
\text { 02 }\end{array}$ & $00: 00: 54$ & $00: 00: 38$ & $00: 00: 38$ & $00: 01: 40$ \\
\hline $\begin{array}{c}\text { USUÁRIO } \\
\text { 03 }\end{array}$ & $00: 01: 20$ & $00: 00: 28$ & $00: 00: 36$ & $00: 00: 20$ \\
\hline $\begin{array}{c}\text { USUÁRIO } \\
\text { 04 }\end{array}$ & $00: 01: 08$ & $00: 00: 25$ & $00: 00: 29$ & $00: 00: 17$ \\
\hline $\begin{array}{c}\text { USUÁRIO } \\
\text { 05 }\end{array}$ & $00: 02: 26$ & $00: 00: 32$ & $00: 00: 30$ & $00: 00: 40$ \\
\hline MÉ́́DIA & $00: 01: 19$ & $00: 00: 31$ & $00: 00: 39$ & $00: 00: 37$ \\
\hline
\end{tabular}

\author{
Tabela 03: Tempo de execução por tarefa e \\ tempo médio \\ Fonte: Dados da Pesquisa
}

Como pode se analisar com facilidade na tabela 03a tarefa um, que consistia em logar e iniciar um novo jogo, foi a que mais demorou a ser desenvolvida, resultando na média de um minuto e dezenove segundos para ser realizada.

Podendo perceber que apesar de cumprirem a tarefa ela foi realizada com certo tipo de dificuldade, afinal era esperado que fosse desenvolvida em média em trinta segundos. Porém o usuário que realizou esta tarefa em menor tempo foi quarenta e seis segundos, o que já é considerado acima do esperado pelos aplicadores do teste. Isso se deu porque todos os usuários se sentiram perdidos no aplicativo procurando por um botão "logar" ou "fazer novo cadastro".

A tarefa dois, que era para desligar a vibração do jogo, foi realizada em menor tempo e dentro do tempo esperado para sua realização. Não houve nenhuma dificuldade ou dúvidas por parte dos usuários em sua realização.

A tarefa três, que era para compartilhar os pontos do jogo em alguma rede social, também foi executada no segundo menor tempo em média. Assim como a segunda tarefa não houve dificuldade ou dúvida por parte dos usuários. Porém a usuária 2 falou se sentir incomodada com o relógio, símbolo para carregar página, pois ela associava com demora.

A quarta tarefa, o logout do aplicativo, pela média se apresenta como a segunda tarefa mais facilmente concluída, dentro de trinta e sete segundos, porém se esperava sua realização dentro de vinte segundos aproximadamente.

No entanto houve usuário que realizou em até um minuto e quarenta segundos. Isso aconteceu porque as pessoas esperavam encontrar este botão na tela principal e ficaram procurando por ele na parte de configurações. No entanto o botão estava localizado na tela de Jogar. 
O usuário 1 ficou entediado ou irritado com o aplicativo e fez o logout pelo botão do celular e não pelo aplicativo como foi pedido na tarefa.

\subsubsection{Respostas do questionário de avaliação de interface}

\begin{tabular}{|c|c|}
\hline NÍVEL DE SATISFAÇÃo DO APLICATIVO \\
\hline Questões & MÉDIA \\
\hline Facilidade na utilização & 4.0 \\
\hline Organização das informações & 4.2 \\
\hline Layout das telas & 4.8 \\
\hline Nomenclatura utilizada nas telas & 4.6 \\
\hline Assimilação das informações & 4.6 \\
\hline A realização do teste & 4.4 \\
\hline
\end{tabular}

Tabela 04:Média dos usuários por questão Fonte: Dados de Pesquisa

\section{Questão 1 - Aponte situações que você achou fácil} utilizar o aplicativo?

Usuário 1: "Iniciação do jogo, compartilhamento, dentre outros"

Usuário 2: "O layout claro e simples"

Usuário 3: "Configurações é bem clara, as pontuações também, a parte de jogar também ficou clara"

Usuário 4: "Achei todas as funções de fácil uso"

Usuário 5: “Tarefa 1”(Iniciar um novo Jogo)

Questão 2 - Aponte situações em que sentiu dificuldades.

Usuário 1: "Botões de ranking"
Usuário 2: "Disposição das opções de jogo confusa. Ex: Dificuldade em achar modo de sair do jogo)

Usuário 3: "Na hora de logar o jogo que fiquei confuso"

Usuário 4: "Não tive nenhuma dificuldade"

Usuário 5: "Tarefa 2"(Mudar a vibração do jogo)

Questão 3 - Sugestão de melhorias

Usuário 1: "Nenhuma"

Usuário 2: "Colocar uma opção de desligar onde já tem o de ligar mas separado (referente a vibração do jogo). Facilitar o modo de saída do jogo"

Usuário 3: "Uma forma de login mais clara"

Usuário 4: "O logar pode ser efetuado antes do jogar"

Usuário 5: "Login na tela inicial"

\subsection{Análise dos resultados}

A partir das médias pelas questões da tabela se identificou que o aplicativo foi satisfatório, pois nenhum quesito ficou abaixo da pontuação 4.0, ou seja um resultado positivo. No entanto as menores médias foram obtidas nas questões relacionadas à facilidade de utilização e organização das informações e os problemas foram identificados pelos próprios usuários nas perguntas discursivas.

Com os resultados obtidos, foi feita uma análise dos problemas citados pelos usuários e detectados pelos observadores, assim como propor suas respectivas alterações.

\section{Análise 1 - A tarefa do login}

A primeira tarefa consistia em logar o jogo, dentre todas foi a que na média demandou mais tempo para ser executado. Além de ter sido citado por três usuários como uma dificuldade, ou seja, $60 \%$ dos pesquisados. $\mathrm{O}$ botão de login estava inserido em 
uma terceira tela após o jogar e todos que fizeram o teste logaram como se já tivesse conta no jogo, o que mostra que talvez a opção novo cadastro não estivesse clara para os usuários.

Proposta de Solução: Quando fosse instalado o jogo ter uma tela de saudação que tivesse duas opções: "Começar ou Jogar" e uma em menor destaque escrita: "Já tenho conta". Após a pessoa fazer um cadastro apareceria a tela principal já existente.

Prioridade: máxima (resolver).

\section{Análise 2 - O logout}

A princípio não estava inserido nas tarefas, mas devido ao tempo que foi gasto para sua execução e além do fato de ser citado como problema pro um usuário foi inserido como um problema na organização do aplicativo. O logout estava inserido em uma tela secundário do novo jogo, o que é confuso e não comum entre aplicativos. Alguns demoraram outros optaram por apenas sair do jogo pelo botão do celular, devido à dificuldade encontrada.
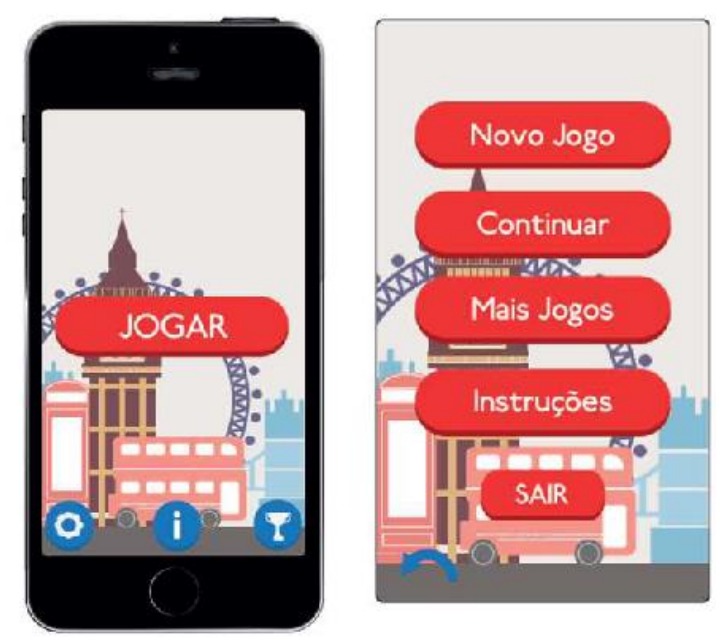

Figura 04 - Layout das telas para parte de logout. Fonte: Dos autores.

Proposta de Solução: Colocar a opção "logout/sair do jogo" na tela principal para facilitar a saída.

Prioridade: máxima (resolver).

\section{Análise 3 - $O$ botão desligar a vibração}

Apesar de não ter causado dúvidas quanto ao botão de desligar, um usuário sugeriu que se o botão fosse alterado facilitaria mais o entendimento da opção.

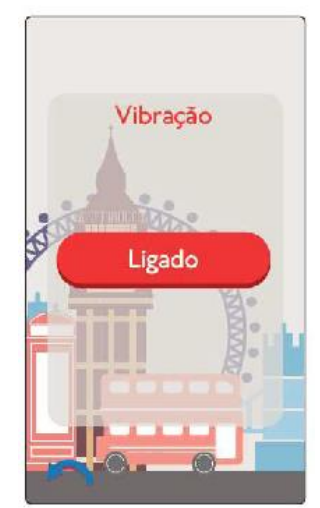

Figura 05 - Layout das telas para desligar a vibração.

Fonte: Dos autores.

Proposta de Solução: Colocar dois botões de ligado e desligado onde alterasse a cor quando um tivesse ativado e outro desativado.

Prioridade: média (resolver se houver de fato a necessidade após mais testes).

\section{Análise 4 - O símbolo de carregar tela}

Apesar de não ter sido citado em nenhuma resposta do questionário, durante a realização das tarefas um usuário reclamou quanto ao símbolo por associar à lentidão e demora. Porém não comprometeu em nada na realização das tarefas e não incomodou nenhum outro usuário.

Proposta de Solução: Substituir o símbolo por alguma animação ou barra de carregamento para excluir a sensação de demora ou travamento do sistema.

Prioridade: média (resolver se houver de fato a necessidade após mais testes).

\section{Análise 5 - $O$ botão de Conquistas}

Um usuário falou da dificuldade com o botão de 
conquistas, apesar de não esclarecer sobre o que exatamente seria. Na tarefa em relação aos pontos também não houve dificuldades na execução e nem dúvidas. Quanto ao ícone ele é amplamente usado em jogos.

Portanto não há dados concretos que possam ser usados para qualquer alteração.

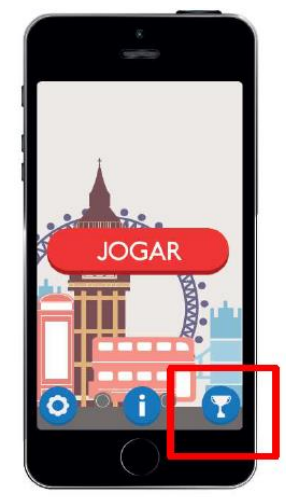

Figura 06 - Layout da tela inicial com o botão de conquista sinalizado.

Fonte: Dos autores.

\section{Considerações Finais}

Este artigo objetivou o desenvolvimento de interfaces para um aplicativo de celular. Foram obtidos resultados que demonstraram o uso e experiências de possíveis usuários do aplicativo. Através da abordagem participativa pode-se permitir uma melhor adaptação efetiva e contundente para aprimorar o aplicativo de forma que possa atender seu público a quem é destinado.

Este estudo faz parte de uma pesquisa mais abrangente em desenvolvimento sobre uma proposta de aplicativo para celular, a qual tem o objetivo final de desenvolver e avaliar um layout aplicando os requisitos de ergonomia e usabilidade. Para o desenvolvimento da pesquisa pretende-se ainda, realizar estudos de campo com um número maior de possíveis usuários a fim de observar a interação direta com o aplicativo funcional.

\section{BIBLIOGRAFIA}

BARANAUSKAS, M. C. C.; ROCHA, H. V. Design e Avaliação de Interface Homem-Computador. São Paulo: UME-USP, 2000.

BRANDÃO, Eduardo Rangel \& MORAES, Anamaria de. Publicidade on-line, ergonomia e usabilidade: $o$ efeito de seis tipos de banner no processo humano de visualização do formato do anúncio na tela do computador e de lembrança da sua mensagem. Dissertação (Mestrado)-PUC-RIO, Rio de Janeiro, 2006.

CABRAL, Isabela \& COUTO, Bernardo.Aascensão dos jogos mobile. In: Eclética, PUC-RIO. Rio de Janeiro - RJ, 2014.

COUTINHO, Gustavo Leuzinger. A Era dos Smartphones: Um estudo Exploratório sobre o uso dos Smartphones no Brasil. Tese (Dissertação) Universidade de Brasília, Brasília, 2014.

CYBIS, Walter; BETIOL, Adriana Holtz \& FAUST, Richard.Ergonomia e Usabilidade: Conhecimentos, Métodos e Aplicações. 2 ed. São Paulo: Novatec Editora, 2010.

DIAS, Cláudia. Avaliação de Usabilidade: conceitos e métodos. Disponível em

$<$ http://www.puc-

campinas.br/revista_ii/frame_segunda_edicao.html>. Acesso em 01 Abril de2016.

FERREIRA, Kátia Gomes. Teste de Usabilidade. Tese( Dissertação) - Universidade Federal De Minas Gerais. Belo Horizonte - MG, 2002.

HIX, Deborah e HARTSON, H. Rex.Developing User Interfaces, Ensuring Usability Through Product \& Process. New York: p. 3. John Wiley\& Sons, Inc., 1993.

JAKOB, Nielsen, Usabilty Engineering, Morgan Kaufmann, Inc. San Francisco, 1993

KULPA, Cínthia Costa; PINHEIRO, Eluza Toledo e DA SILVA, Régio Pierre. A influência das cores na usabilidade de interfaces através do design centrado no comportamento cultural do usuário. 
In: Perspectivas em Gestão \& Conhecimento, João Pessoa, Número Especial, p.119-136,out: 2011.

LOUREIRO, Eduardo Pinheiro. Design centrado no usuário e as limitações do mercado de produtos interativos: Pesquisa e análise sobre indicadores para uma conciliação entre pesquisa e mercado. Dissertação (Pós-Graduação). PUC-MG, Belo Horizonte - MG, 2008.

MOREIRA, Fábio Eduardo. Desenvolvimento de jogos eletrônicos multiusuário para dispositivos móveis. Dissertação (graduação) - Faculdade Farias Brito. Fortaleza - CE, 2011.

NEIL, T. Padrões de Design para aplicativos móveis. São Paulo: NOVATEC Editora; Sebastopol: O’Riley, 2012.

PADOVANI, S. \& RIBEIRO, M. A. Cardsorting: adaptação da técnica para aplicação ao design de sistemas de informação não digitais. São Paulo | v. 10 |n. 3 [2013], p. $293-312$.

PASSOS, Jaire Ederson. Metodologia para o design de interface de ambiente virtual centrado no usuário. Dissertação (mestrado) - Universidade Federal do Rio Grande do Sul. Porto Alegre - RS, 2010.

PEREIRA, Wallas Andrade. Eddy: demo de um jogo para telefone celular. Dissertação (graduação) Universidade Estadual do Sudoeste da Bahia. Vitória da Conquista - BA, 2012.

PORTO, Fabiano. Aplicativos Mobile: definições, história e previsões. In: TecTriade Brasil - Estratégia e Inteligência Digital. Nov. 2012.

SANTA ROSA, José Guilherme \& MORAES, Anamaria. Avaliação e Projeto no Design de Interfaces.Teresópolis, RJ: 2AB, 2010.

SNYDER, Carolyn. Paper Prototyping: The fast and easy way to define user interfaces. San Francisco: Morgan Kaufmann Publishers, 2003.

RUBIN, Jeffrey. Handbook of Usability Testing:
How to Plan, Design and Conduct Effective Tests. New York: John Wiley \& Sons, Inc., 1994.

WODTKE, C.; GOVELLA, A. Information Architecture: Blueprints for the Web.Berkeley: New Riders, 20 